\title{
Sinorhizobium meliloti Controls Nitric Oxide-Mediated Post-Translational Modification of a Medicago truncatula Nodule Protein
}

\author{
Pauline Blanquet, ${ }^{1,2}$ Liliana Silva, ${ }^{3}$ Olivier Catrice,,${ }^{1,2}$ Claude Bruand,,${ }^{1,2}$ Helena Carvalho, ${ }^{3}$ and \\ Eliane Meilhoc ${ }^{1,2}$ \\ ${ }^{1}$ Institut National de la Recherche Agronomique, Laboratoire des Interactions Plantes-Microorganismes, UMR441, \\ Castanet-Tolosan, France; ${ }^{2}$ Centre National de la Recherche Scientifique, Laboratoire des Interactions Plantes- \\ Microorganismes, UMR2594, Castanet-Tolosan, France; and ${ }^{3}$ Laboratório de Biologia Molecular da Assimilação do Azoto, \\ Instituto de Biologia Molecular e Celular, Universidade do Porto, Rua do Campo Alegre 823, 4150-180 Porto, Portugal
}

Submitted 28 May 2015. Accepted 17 September 2015.

\begin{abstract}
Nitric oxide (NO) is involved in various plant-microbe interactions. In the symbiosis between soil bacterium Sinorhizobium meliloti and model legume Medicago truncatula, NO is required for an optimal establishment of the interaction but is also a signal for nodule senescence. Little is known about the molecular mechanisms responsible for NO effects in the legumerhizobium interaction. Here, we investigate the contribution of the bacterial NO response to the modulation of a plant protein post-translational modification in nitrogen-fixing nodules. We made use of different bacterial mutants to finely modulate NO levels inside $M$. truncatula root nodules and to examine the consequence on tyrosine nitration of the plant glutamine synthetase, a protein responsible for assimilation of the ammonia released by nitrogen fixation. Our results reveal that $S$. meliloti possesses several proteins that limit inactivation of plant enzyme activity via NO-mediated post-translational modifications. This is the first demonstration that rhizobia can impact the course of nitrogen fixation by modulating the activity of a plant protein.
\end{abstract}

Leguminous plants are capable of growing under nitrogenlimiting conditions, due to their ability to establish an endosymbiosis with soil bacteria called rhizobia. Rhizobia interact with legume roots, on which they induce the formation of new organs, called nodules, wherein they differentiate into bacteroids able to reduce atmospheric nitrogen $\left(\mathrm{N}_{2}\right)$ into ammonia $\left(\mathrm{NH}_{3}\right)$ to the benefit of the host plant. In exchange, plants provide bacteria with a niche as well as energy in the form of carbon sources. Rhizobium-legume symbioses have been characterized in detail at the cytological and genetic levels, and a number of bacterial and plant genes required for bacterial infection, nodule formation, and functioning have been identified (Jones et al. 2007; Oldroyd et al. 2011; Terpolilli et al. 2012).

P. Blanquet and L. Silva contributed equally to the work.

Corresponding author: E. Meilhoc; Telephone: +33 561285320;

E-mail: Eliane.Meilhoc@toulouse.inra.fr

*The $\boldsymbol{e}$-Xtra logo stands for "electronic extra" and indicates that seven supplementary figures are published online.

@ 2015 The American Phytopathological Society
Nitric oxide (NO), a well-known diffusible gas signal molecule in mammalian cells, is emerging as a molecule of prime importance in plant biology (Besson-Bard et al. 2008; Mur et al. 2006, 2012; Yu et al. 2014). Interestingly, NO is present at various stages of the rhizobium-legume symbioses (Meilhoc et al. 2011; Wang and Ruby 2011). Indeed NO was detected (either directly, using NO-specific fluorescent probes, or indirectly, using a rhizobium NO-biosensor strain, or through the detection of nitrosyl-leghemoglobin) in nitrogen-fixing nodules of Medicago truncatula, Medicago sativa, Lotus japonicus, and soybean (Baudouin et al. 2006; Mathieu et al. 1998; Nagata et al. 2008; Pii et al. 2007; Sánchez et al. 2010). NO is also present during the first steps of the interaction. Indeed, a transient NO production was detected on the surface of $M$. sativa, L. japonicus, and Trifolium repens roots $4 \mathrm{~h}$ after inoculation and only when the cognate bacterial symbionts were used (Nagata et al. 2008). NO was also detected in infected $M$. truncatula root hairs, both in the colonized curls and along the infection threads as well as in cells of nodule primordia (del Giudice et al. 2011).

The role played by NO in symbiosis is still puzzling, but it is emerging that NO might have opposite effects, depending on the step of the interaction. Indeed, by using genetic and pharmacological approaches, it was shown that NO has a beneficial role during the first steps of symbiosis, since it is important for one or both optimal infection or nodulation (del Giudice et al. 2011). It also has a positive role in the mature nodule, in which it could serve a respiratory function, especially in conditions of oxygen limitation (for instance under flooding) (Horchani et al. 2011). On the other hand, NO has a negative effect in mature nodules, since it has been shown to inhibit nitrogenase activity (Kato et al. 2010; Trinchant and Rigaud 1982) and has been suggested to be a signal in physiological or stress-induced nodule senescence (Cam et al. 2012).

It can be suspected that the effect of NO will depend upon its localization and concentration within the nodule. NO levels result from a balance between its synthesis and its degradation Nitrate reductase has been shown to be an important source of NO in mature nodules (Horchani et al. 2011), and both symbiotic partners (bacteria and plant) were shown to participate significantly in NO synthesis in determinate (soybean) as well as indeterminate (Medicago spp.) nodules (Horchani et al. 2011; Sánchez et al. 2010). On the other hand, plant hemoglobins (nonsymbiotic hemoglobins but, also, leghemoglobins and truncated hemoglobins) have been shown 
to be involved in NO degradation (Gupta et al. 2011). We have also shown that two $S$. meliloti proteins, the flavohemoglobin (Hmp) and the NO reductase (Nor), are major NO detoxifying enzymes essential in maintaining a balanced $\mathrm{NO}$ concentration and an efficient symbiosis (Cam et al. 2012; Meilhoc et al. 2013). Furthermore, we have identified two genes (nnrS1 and $n n r S 2$ ), which encode heme and copper-containing membrane proteins whose homologs in Vibrio cholerae and Rhodobacter sphaeroides 2.4 .1 have been shown to be important in resistance to nitrosative stress in culture (Stern et al. 2012, Arai et al. 2013). Hence, endosymbiotic bacteria, such as many microbes and, especially, pathogens, possess several different systems to degrade NO as a first defense strategy to survive to this potentially toxic molecule.

Even though little is known about the molecular mechanisms responsible for $\mathrm{NO}$ effects in legume-rhizobium interactions, it is now recognized that NO not only influences gene expression but could also act through post-translational modifications of target proteins (Astier and Lindermayr 2012; Besson-Bard et al. 2008). Indeed, a large number of studies are now dedicated to the two main protein post-translational modifications that are specific to NO action and signaling, i.e., $S$-nitrosylation and tyrosine nitration. About $15 S$-nitrosylated proteins have been well characterized in plants, many of them being key proteins of the signal transduction pathway that leads to plant resistance against pathogens, drawing a first outline of the involvement of $\mathrm{NO}$ in plant immune signaling. In the model symbiotic system Sinorhizobium meliloti-M. truncatula, about $80 S$-nitrosylated proteins have been identified in mature nodules, but the effect of $S$-nitrosylation on protein activity or function or both remains to be determined (Puppo et al. 2013). There have been relatively few studies on tyrosine nitration, possibly because of the irreversible nature of this modification, which makes it a less-attractive regulatory switch, although some evidence of enzymatic and nonenzymatic mechanisms of denitration is available (Abello et al. 2009). Interestingly, protein tyrosine nitration appears as a prevalent post-translational modification throughout pea root development and intensifies during root senescence (Begara-Morales et al. 2013). Very recently, it has been shown that leghemoglobin, an abundant hemeprotein of

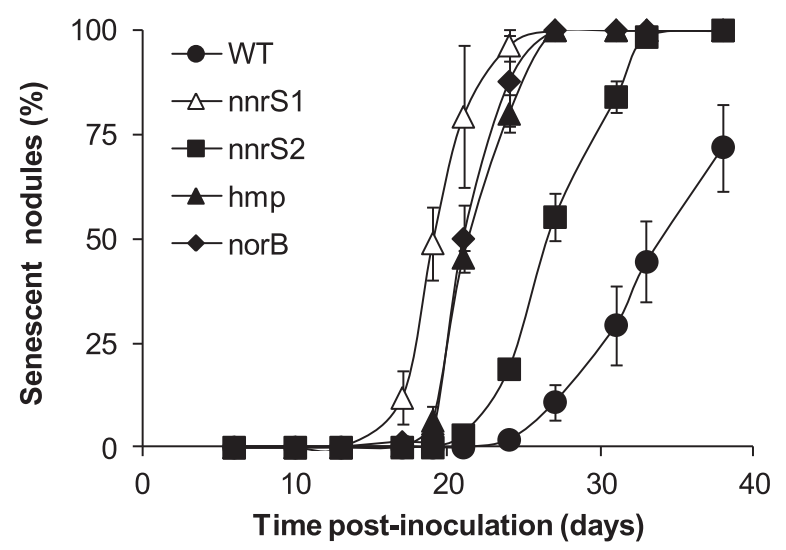

Fig. 1. Nodule senescence kinetics of Medicago truncatula inoculated with Sinorhizobium meliloti mutant strains. M. truncatula seedlings were inoculated with S. meliloti strains GMI1495 (WT), CBT619 (nnrS1), CBT1418 (nnrS2), CBT613 ( $h m p$ ), or CBT618 (norB). At each time point, total and senescent nodules were counted for each of three independent series of ten plants; hence, the percentage of senescent nodules was determined for each series. The mean \pm standard error is shown on the graph. The kinetics of nodule appearance was similar for the different strains (not shown). At time point 17 days postinoculation, when the first senescent nodules appear, the total number of nodules counted in a series was 70 to 110 . legume nodules, is tyrosine-nitrated in bean and soybean (Sainz et al. 2015). In M. truncatula, only one protein, the glutamine synthetase (GS), has been fully characterized as a target of tyrosine nitration in nodules (Melo et al. 2011). This protein is of major importance in symbiosis, because it is responsible for the assimilation of the ammonia released by bacterial nitrogen fixation into glutamine, which is then used as a building block for all other nitrogen-containing compounds in the plant. The effect of NO on protein modification and enzyme activity has been previously described and it has been shown that tyrosine nitration negatively impacts GS activity (Melo et al. 2011).

The deeper knowledge of the role of NO in plant-symbiont interactions is still relatively limited by the lack of plant mutants with altered NO production. Therefore, experimental strategies rely on the use of NO donors, which are compounds that release NO when applied to biological systems and are supposed to mimic an endogenous NO-related response. However, it is often difficult to discriminate between physiologically relevant and pharmacological effects depending upon the nature of the NO donor application method as well as possible effects of spent donor products (Filippou et al. 2012; Procházková and Wilhelmová 2011). In this work, we described two new $S$. meliloti mutants affecting NO levels in $M$. truncatula root nodules and triggering premature senescence of these organs. Thus, we made use of a range of bacterial mutants to finely modulate the endogenous levels of NO inside the nodules, and we show that tyrosine nitration of the plant protein GS correlates with NO concentration. These data imply that bacterial proteins may indirectly control NO-induced posttranslational modifications of plant proteins.

\section{RESULTS}

The S. meliloti nnrS1 and nnrS2 mutants are affected in the maintenance of an efficient symbiosis with $M$. truncatula.

$\mathrm{NnrS}$ was first identified in Rhodobacter sphaeroides (Bartnikas et al. 2002) and displays a topological conservation with NORs and heme-copper oxidases (HCO) (Pei et al. 2014; Sousa et al. 2012). Experimental studies and genomic context analyses suggest that the NnrS protein family could function in one or both the denitrification pathway or detoxification of reactive molecules such as NO. Thus, NnrS has been shown to

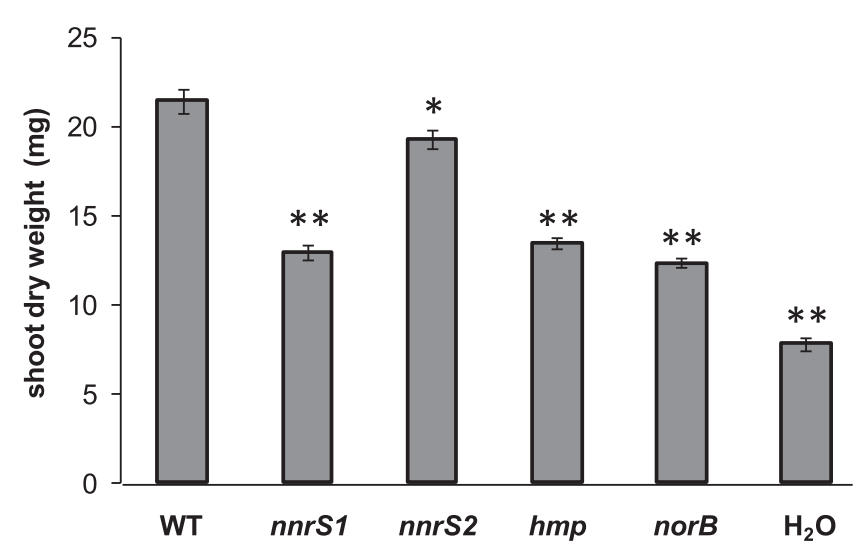

Fig. 2. Shoot dry weight of Medicago truncatula inoculated with nnrS mutant strains. M. truncatula seedlings were inoculated with Sinorhizobium meliloti strains GMI1495 (WT), CBT619 (nnrS1), CBT1418 (nnrS2), CBT613 ( $h m p$ ), or CBT618 (norB). The shoot dry weight of about 30 plants was measured between 38 and 40 days postinoculation. The mean \pm standard error is shown on the graph. Asterisks (* and **) indicate significant difference $(P<0.05$ and $P<0.01$ respectively) when compared with the control (WT strain), according to student's $t$ test. 
be part of the arsenal defense of Vibrio cholerae and Rhodobacter sphaeroides 2.4 .1 against the toxic effect of NO (Arai et al. 2013; Stern et al. 2012). In addition, gene disruption experiments showed that $\mathrm{NnrS}$ is important in $V$. cholerae and Neisseria meningitidis for colonization of intestines in the presence of $\mathrm{NO}$, suggesting a role for $\mathrm{NnrS}$ in the defense against NO (Jamet et al. 2013; Stern et al. 2012, 2013).

To test whether NnrS proteins have a biological function in symbiosis, we used nnrS1 and nnrS2 mutant strains to inoculate $M$. truncatula seedlings. We have previously shown that bacterial mutants of the NO-degrading enzymes Hmp and Nor display an early nodule-senescence phenotype correlating with an increased NO level inside nodules (Cam et al. 2012; Meilhoc et al. 2013). Nodule senescence is characterized macroscopically by a color shift from pink to green, associated with degradation of the plant leghemoglobin (Supplementary Fig. S1). Hence, to evaluate the senescence phenotype, we monitored the color of nodules over a period of 6 weeks postinoculation (wpi). As a comparison, we monitored, in parallel, the senescence of nodules induced by $h m p$ and norB mutants. As already published, plants inoculated with these mutants displayed an early nodule-senescence phenotype, since the first senescent nodules
WT
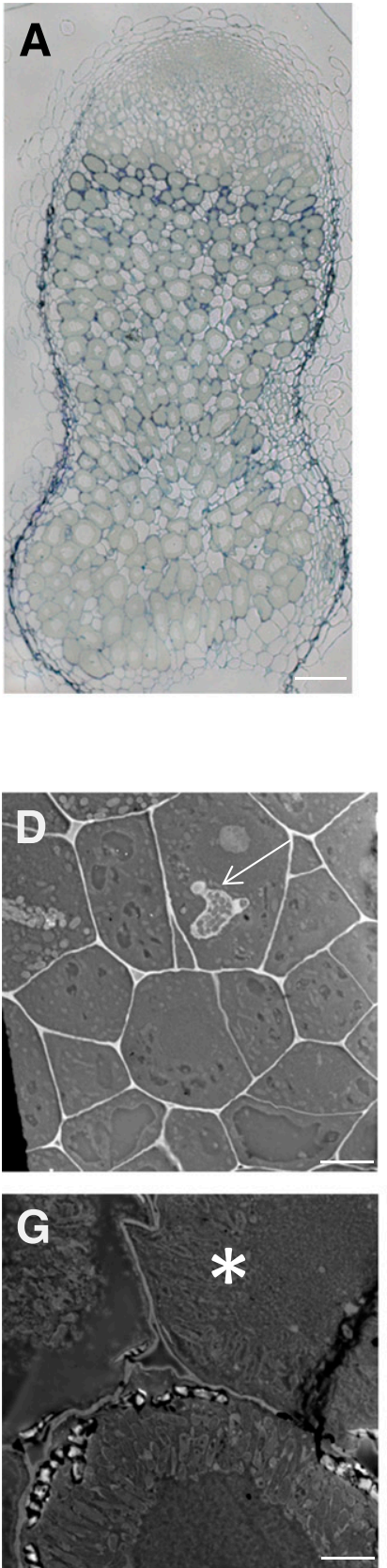

$n n r S 1$

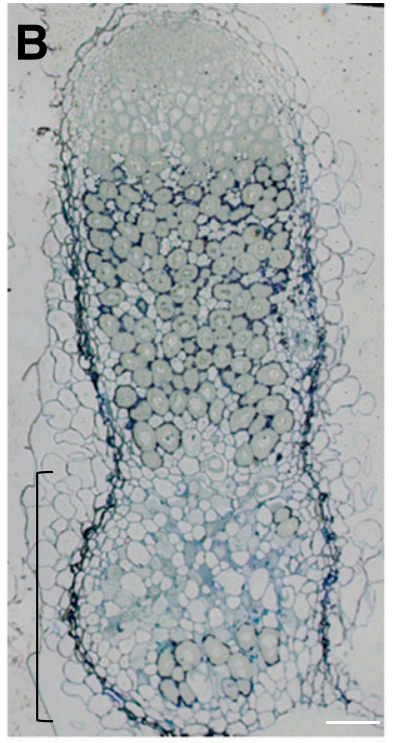

$n n r S 1$
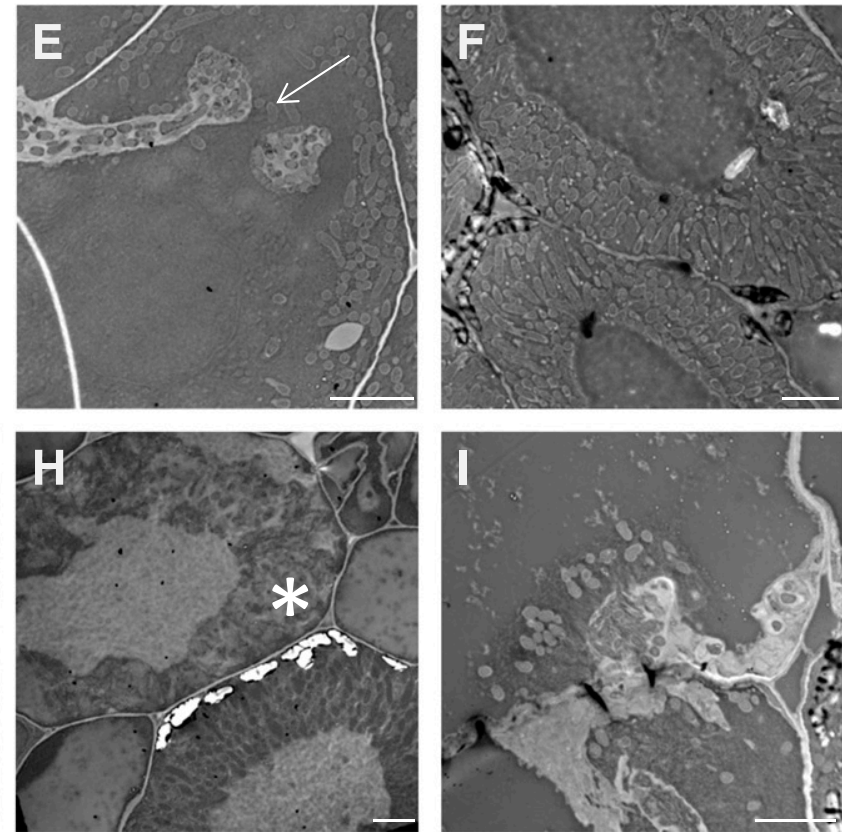

nnrS2
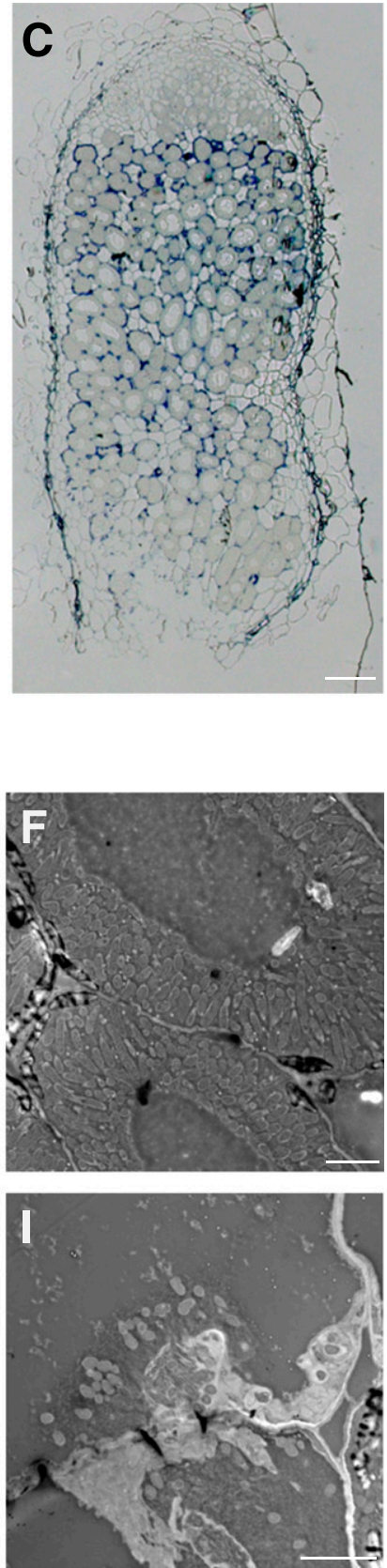

Fig. 3. Microscopic characterization of Medicago truncatula nodules elicited by nnrS mutant strains. M. truncatula seedlings were inoculated with Sinorhizobium meliloti strains A, GMI11495 (WT), B, CBT619 (nnrS1), or C, CBT1418 (nnrS2). Nodule senescence was observed by means of toluidine bluestaining on longitudinal thin $(2 \mu \mathrm{m})$ nodule sections. The nodule-senescence zone is indicated by a bracket. Scale bars $=100 \mu \mathrm{m}$. Ultrastructural changes were observed by means of transmission electron microscopy on ultrathin (70 to $80 \mathrm{~nm}$ ) sections of 20-day-old nodules occupied by the $S$. meliloti CBT619 ( $n n r S 1$ ) mutant. D and E, Cells from the infection zone (zone II) displaying infection threads releasing bacteria in the plant cells (indicated by the white arrows), $\mathbf{F}$, cells from the fixation zone (zone III) with differentiated bacteroids, $\mathbf{G}$ and $\mathbf{H}$, cells from the senescent zone (senescent plant cells indicated with an asterisk), and $\mathbf{I}$, reinvasion of senescent cells by undifferentiated saprophytic bacteria. Scale bars $=25 \mu \mathrm{m}$. 
appeared at 19 days postinoculation (dpi), as compared with 24 dpi for the wild-type (WT) strain (Fig. 1). In addition, the rate of appearance of senescent nodules was faster with the mutants than with the WT strain. Interestingly, senescent nodules appeared earlier with the $n n r S 1$ mutant as compared with the hmp and norB mutants. Indeed, at $17 \mathrm{dpi}$, as many as $11 \%$ of the nodules were already senescent and, 1 week later, all the nodules were senescent. This phenotype was complemented by introducing a multicopy plasmid carrying the $n n r S 1$ gene into

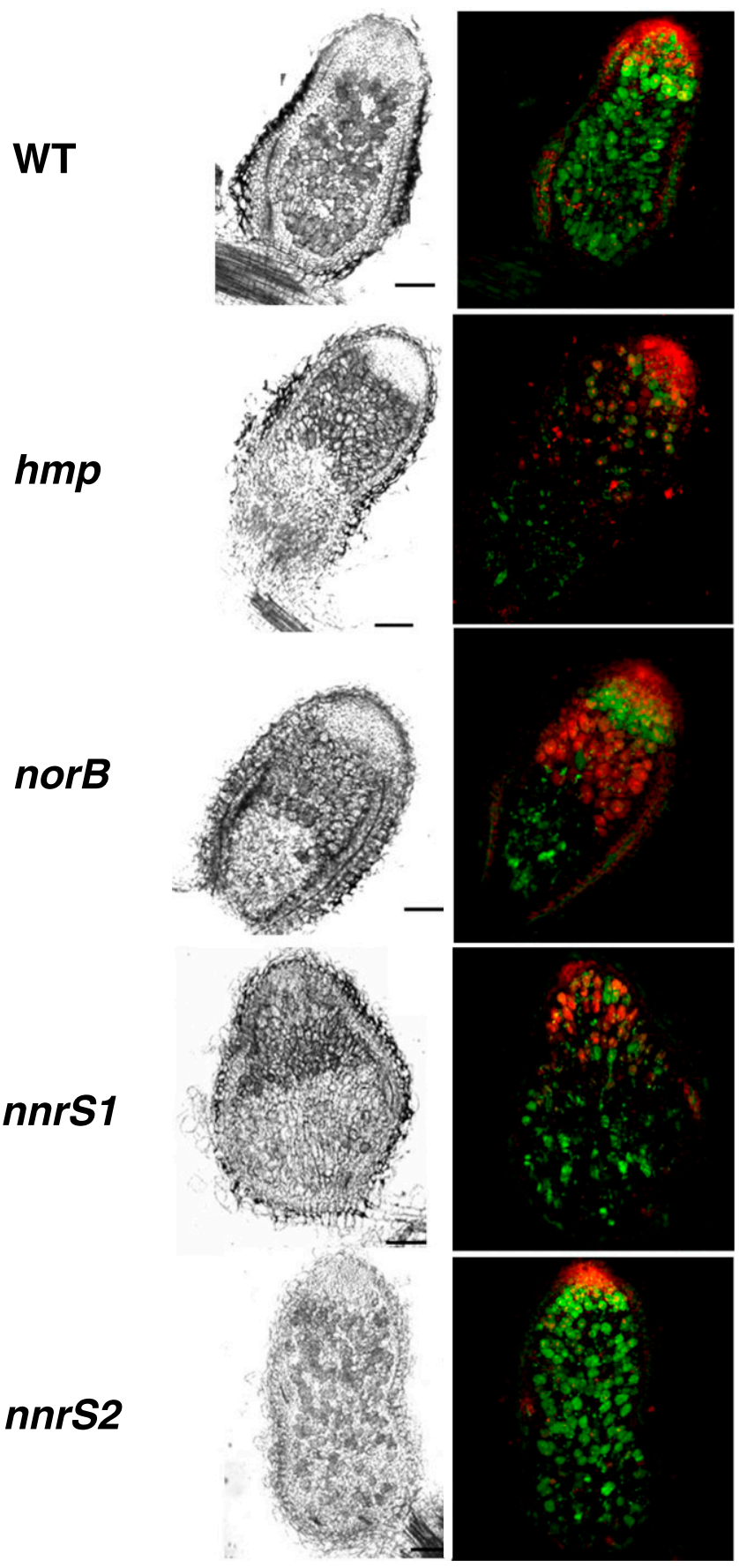

Fig. 4. Live and dead staining of wild type (WT) and mutant bacteroids Medicago truncatula seedlings were inoculated with the Sinorhizobium meliloti strains GMI11495 (WT), CBT613 (hmp), CBT618 (norB), CBT619 (nnrS1), or CBT1418 (nnrS2). At 19 days postinoculation, nodule sections $(60 \mu \mathrm{m})$ were stained with a mixture of SYTO9 and propidium iodide (PI) to test the viability of bacteroids. Viable cells are stained in green by SYTO9 and dying cells are stained in red with PI. Representative images obtained by confocal microscopy are shown. Scale bars $=100 \mu \mathrm{m}$. the nnrS1 mutant strain (Supplementary Fig. S2). The complementation was only partial, probably due to the instability of the plasmid in planta in the absence of selection pressure. However, full complementation was observed in an in vitro NO resistance assay in which selection can be maintained (unpublished data).

The symbiotic phenotype of the nnrS2 mutant was intermediate between the WT and the $h m p$ or norB phenotypes. Actually, the first senescent nodules appeared only 3 wpi and the senescence kinetics were slower than with the other mutants. However, all the $n n r S 2$-elicited nodules were senescent 5 wpi.

We observed a good correlation of the nodule-senescence phenotype with the plant shoot dry weight (Fig. 2). Indeed, plants inoculated with the nnrSl mutant displayed a lower average dry weight than those inoculated with the WT strain (40\% reduction), comparable to that obtained with norB or hmp mutant strains. $n n r S 2$ had only a weak but significant effect on the plant shoot dry weight.

In order to better characterize the nodule-senescence process induced by $n n r S$ mutant strains, we performed microscopic analyses of sections of WT-, $n n r S 1-$, and $n n r S 2$-elicited nodules at 3 wpi. Thin longitudinal sections of WT nodules stained with toluidine blue showed the typical zonation of indeterminate nodules, i.e., the meristem (ZI), the infection zone (ZII), the interzone II-III with cells containing starch granules (stained in dark purple), and a large fixation zone (ZIII) with mainly healthy cells (Fig. 3A). As expected, no senescence zone was visible in the WT nodules at this stage. nnrS1-elicited nodules displayed an extensive senescence zone (poorly-stained cells, ZIV) (Fig. 3B). Nodules elicited by the $n n r S 2$ mutant generally did not present a marked senescence zone and were comparable at 3 wpi to WT nodules, although some senescent cells were occasionally observed (Fig. 3C).

Transmission electron microscopy (TEM) was used to identify ultra-structural changes in nodule cells. We performed similar studies with $\mathrm{hmp}$ - and norB-elicited nodules as controls. Only results obtained with $n n r S 1$ nodules are shown in Figure 3D through I. The pictures show bacteria properly released from the infection threads in ZII (Fig. 3D and E) and the presence of elongated bacteroids in ZIII (Fig. 3F). Hence, bacteroid differentiation does not seem to be affected in nodules elicited by $n n r S 1$ or $n n r S 2$ mutants. Similar observations were made in nodules occupied by $h m p$ or norB mutants (Supplementary Fig. S3)

TEM pictures from the central zone of the $n n r S 1$-elicited nodules revealed cells with many vesicles and much membrane debris, as expected for a senescence zone (Fig. 3G and $\mathrm{H})$. A saprophytic zone was also observed, in which infection threads appeared to be enlarged, releasing a large number of rhizobia into the degraded infected cells (Fig. 3I), as was also the case in hmp and norB mutants or in other early nodulesenescence mutants (Timmers et al. 2000). This was in striking contrast to WT and $n n r S 2$-elicited nodules, in which infected cells were filled with intact symbiosomes and did not show any signs of degradation at this time point (Supplementary Fig. S4).

To investigate the viability of the mutant bacteroids, we incubated nodule sections with the Live/Dead Backlight probe (Invitrogen). Living bacteria are stained green by Syto 9 , whereas dead bacteria are stained red by propidium iodide (PI). At 3 wpi, WT as well as $n n r S 2$ bacteroids fluoresced green, indicating that these bacteroids were viable (Fig. 4). As already described (Cam et al. 2012), PI red staining was observed with the $h m p$ bacteroids, suggesting their rapid death in plant cells. A similar observation is reported here for nor $B$ bacteroids. $n n r S 1$ nodules also displayed red-stained bacteroids. However, 
these nodule sections were poorly stained and displayed a dark proximal zone, probably due to their more pronounced senescence phenotype (Fig. 4) with degraded plant and bacteroid cells. Residual green staining in this zone was likely due to saprophytic bacteria or bacteria contained in infection threads (Timmers et al. 2000).

Together, these results show that $n n r S 1$ and, to a lesser extent, $n n r S 2$ mutant strains display an early nodule-senescence phenotype. The nnrS2 mutant did not induce major subcellular alterations at $3 \mathrm{wpi}$, in agreement with a nodule-senescence phenotype appearing later than with the other mutants ( $n n r S 1$, $h m p$, or norB). Finally, bacteroids made by nnrS1 mutant strains are not affected in their differentiation but die rapidly in the plant cells.

\section{NO content inside the nodule depends upon the strain used to inoculate $M$. truncatula.}

Since $n n r S 1$ and $n n r S 2$ mutants are defective in bacterial NO resistance, we wondered whether their early nodule-senescence phenotype correlates with a high NO content in nodules. We, therefore, performed a quantitative assay based on the detection of $\mathrm{NO}$ diffusing from entire nodules with a nonpermeable NO-specific fluorescent dye (4,5-diaminofluorescein [DAF-2]) (Horchani et al. 2011). The results obtained for nodules collected at 14, 18, and 26 days are shown in Figure 5. As previously described, we observed a $36 \%$ increase in the NO content of hmp-elicited nodules collected at $18 \mathrm{dpi}$, in comparison with WT nodules (Cam et al. 2012). A slight increase was already detectable at $14 \mathrm{dpi}(12 \%$ increase) and the maximum increase $(100 \%)$ was detected at 26 dpi. The results obtained for the nor $B$ mutant were comparable. Interestingly, in $n n r S 1$-elicited nodules, a large increase $(39 \%)$ in the NO level was already observed at $14 \mathrm{dpi}$, to reach $50 \%$ at $18 \mathrm{dpi}$ and $100 \%$ at 26 dpi. On the other hand, an increase (50\%) of the NO level in nodules elicited by the $n n r S 2$ mutant strain was only observed at 26 dpi.

These results were confirmed qualitatively by using, not only the permeable NO-specific fluorescent dye DAF-2DA (4,5diaminofluroescein-diacetate) on nodule sections (Supplementary Fig. S5) but, also, a complementary approach based on the use of a reporter plasmid carrying a transcriptional fusion to the promoter of SMa1289, an S. meliloti gene specifically induced by NO (de Bruijn et al. 2006; del Giudice et al. 2011; Meilhoc et al. 2010). The WT as well as $n n r S 1$ and $n n r S 2$ mutant strains carrying this plasmid were used to inoculate $M$. truncatula seedlings. Expression of the fusion was assessed at 3 and 4 wpi on nodule sections by X-gal staining and microscopic analysis (Supplementary Fig. S6). Blue staining was observable only at 4 wpi in WT nodules. A strong blue staining was already visible at 3 wpi and was very intense at 4 wpi in $n n r S 1$ nodules. In $n n r S 2$ nodules, blue staining was mostly detectable in interzone II-III at 3 wpi and spread to a few cells in ZIII at 4 wpi.

These results confirm that the nnrS1 mutant forms nodules containing a greater amount of $\mathrm{NO}$ as compared with the WT strain. The NO level in nodules occupied by the $n n r S 2$ mutant was lower than in $n n r S 1$ nodules, and the increase seemed restricted to the cell layers in interzone II-III. Thus, we have, now, a collection of bacterial mutants giving rise to a range of nodule NO levels when used to infect $M$. truncatula plants.

\section{Tyrosine nitration of the plant GS is enhanced in nodules elicited by $h m p$ and $n n r S$ mutants.}

We have identified four $S$. meliloti mutants ( $h m p$, norB, $n n r S 1$, and $n n r S 2$ ) that result in increased NO content inside nodules. Interestingly, each mutant triggers an early-senescence phenotype, even though NO-protecting plant proteins (i.e., hemoglobins) are functional. One hypothesis is that Hmp, Nor, and NnrS are dedicated to protect essential bacterial proteins such as nitrogenase or tricarboxylic acid cycle enzymes, which are known to be sensitive to NO (Kato et al. 2010; Stern and Zhu 2014; Trinchant and Rigaud 1982). Nevertheless, we wondered whether plant proteins might also be affected.

To evaluate whether mutations in the bacterial NO-related proteins have repercussions on the plant side, we quantified GS nitration in nodules formed by different rhizobial mutants (hmp, nnrS1, and nnrS2), using a sandwich enzyme-linked immunosorbent assay (ELISA) (Fig. 6). Indeed, to date, GS is the only protein that has been shown to be post-translationally modified by NO (through tyrosine nitration) in root nodules of M. truncatula (Melo et al. 2011).

GS tyrosine nitration, polypeptide content, and enzymatic activity were compared in nodules elicited by WT, hmp, nnrS1, and $n n r S 2$ mutant strains at $3 \mathrm{wpi}$ as well as nodules formed by a strain overexpressing $h m p$ from a constitutive promoter carried on a multicopy plasmid $\left(h m p^{++}\right)$. This strain was previously shown to delay nodule senescence and to decrease the NO content inside nodules (Cam et al. 2012).

GS exists in the plant as a number of isoenzymes that are located both in the cytosol (GS1) and in the plastids (GS2) and are encoded by a small family of genes (four in M. truncatula). GS nitration was found to be significantly increased in nodules induced by the $h m p$ (Fig. 6C) and nnrS1 (Fig. 6F) mutant strains, as compared with the WT, correlating with decreased GS activity (Fig. 6A and D, respectively). Conversely, GS tyrosine nitration was significantly reduced and GS activity was increased in nodules induced by the rhizobial strain overexpressing hmp (Fig. 6A and C). The GS polypeptide content of both the cytosolic- and the plastid-located isoenzymes was also influenced in nodules formed by the different rhizobial strains (Fig. 6B and E). When the endogenous nodule NO content was higher, which is the case of hmp- and nnrS1- elicited nodules, both the cytosolic- (GS1) and the plastid-located (GS2) polypeptide content were reduced, as compared with WT nodules, whereas in $h m p^{++}$-induced nodules, both GS1 and GS2 polypeptides were slightly more abundant. GS nitration and enzyme

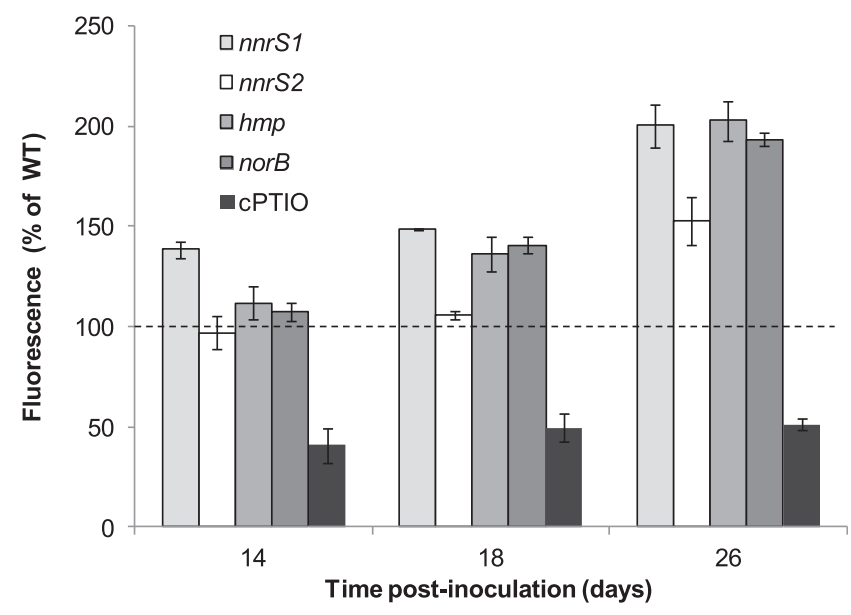

Fig. 5. Nitric oxide (NO) production by Medicago truncatula nodules Seedlings were inoculated with Sinorhizobium meliloti strains GMI11495 (wild type [WT]), CBT619 (nnrS1), CBT1418 (nnrS2), CBT613 (hmp), or CBT618 (norB). NO production by nodules was measured at 14, 18, and 26 days postinoculation, using the nonpermeable fluorescent probe diaminofluorescein-2. In a control experiment, $1 \mathrm{mM}$ cPTIO was added $30 \mathrm{~min}$ before addition of the probe to WT nodules. Fluorescence was expressed as a percentage of the fluorescence obtained with WT nodules at the same time point. Data are means \pm standard errors of three independent experiments (assayed in duplicate). The dotted line indicates the value of the WT. 
activity were unaffected in the nodules formed by the $n n r S 2$ mutant, which is consistent with the fact that NO content was not significantly modified at this time point in the $n n r S 2$-occupied nodules (Fig. 6D and F).

As a whole, our results indicate that GS nitration is positively correlated with NO content inside the nodules, suggesting that the bacterial proteins under study are important to prevent NOmediated GS inactivation.

\section{DISCUSSION}

NO produced during infection of plant or animal cells by pathogens plays a key role in host defense mechanisms. In symbiotic interactions, the role of NO is still obscure, although NO was shown to be present at all stages of the interaction. Hence in both types of interactions, bacteria are in contact with NO and must develop a defense based on different strategies (Bowman et al. 2011; Stern and Zhu 2014). The most obvious strategy to cope with nitrosative stress is to directly remove NO.
Several bacterial enzymes are known to convert NO into less toxic molecules, such as nitrate or nitrous oxide. S. meliloti is the unique rhizobium for which a comprehensive transcriptomic analysis has been performed to identify the entire NO stimulon (Meilhoc et al. 2010). Among the genes whose expression is upregulated by $\mathrm{NO}$, two have been shown to be involved in NO degradation, namely, hmp and nor. We have already shown that both proteins are important in symbiosis, since inoculation of the model legume $M$. truncatula with bacteria mutated in one of these proteins caused an early senescence of nodules (Cam et al. 2012; Meilhoc et al. 2013).

Here, we started a characterization of two new players (NnrS1 and NnrS2) in S. meliloti NO resistance. Both genes belong to the NO stimulon (Meilhoc et al. 2010) and their expression is dependent upon the NO-specific regulator NnrR. The results presented here show that $n n r S$ mutant strains, when inoculated to $M$. truncatula, produced nodules containing more NO content than the WT. This was verified using two complementary strategies. The first one made use of specific

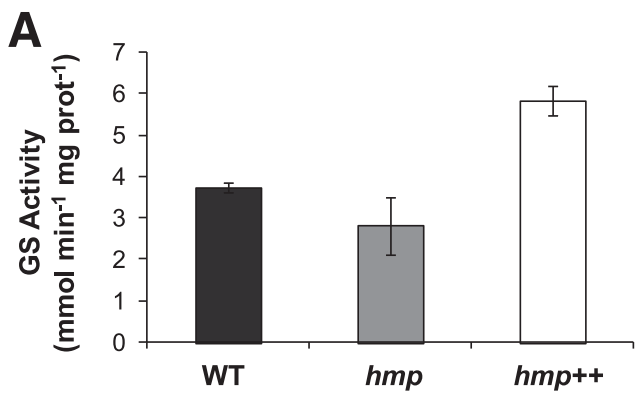

D
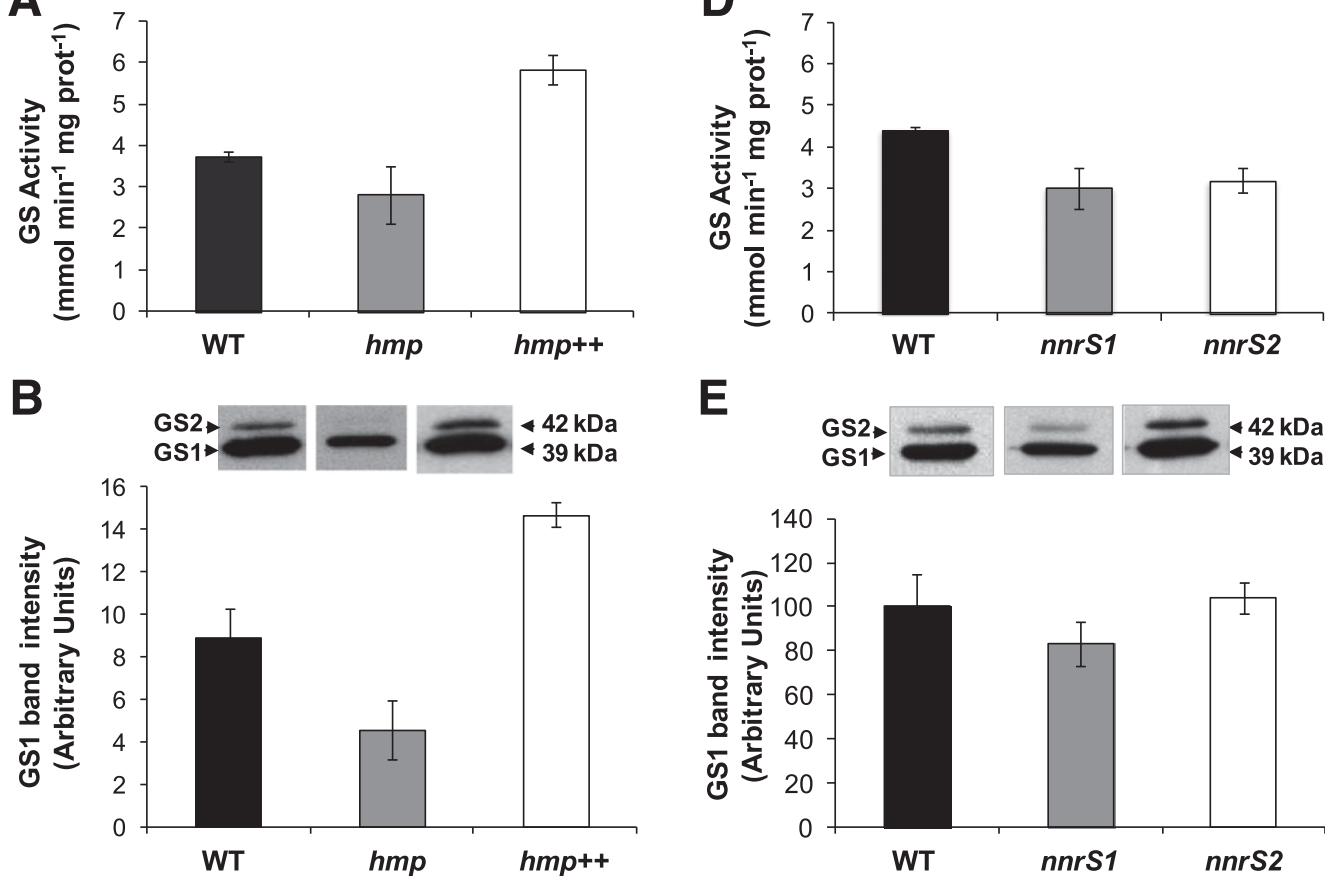

E
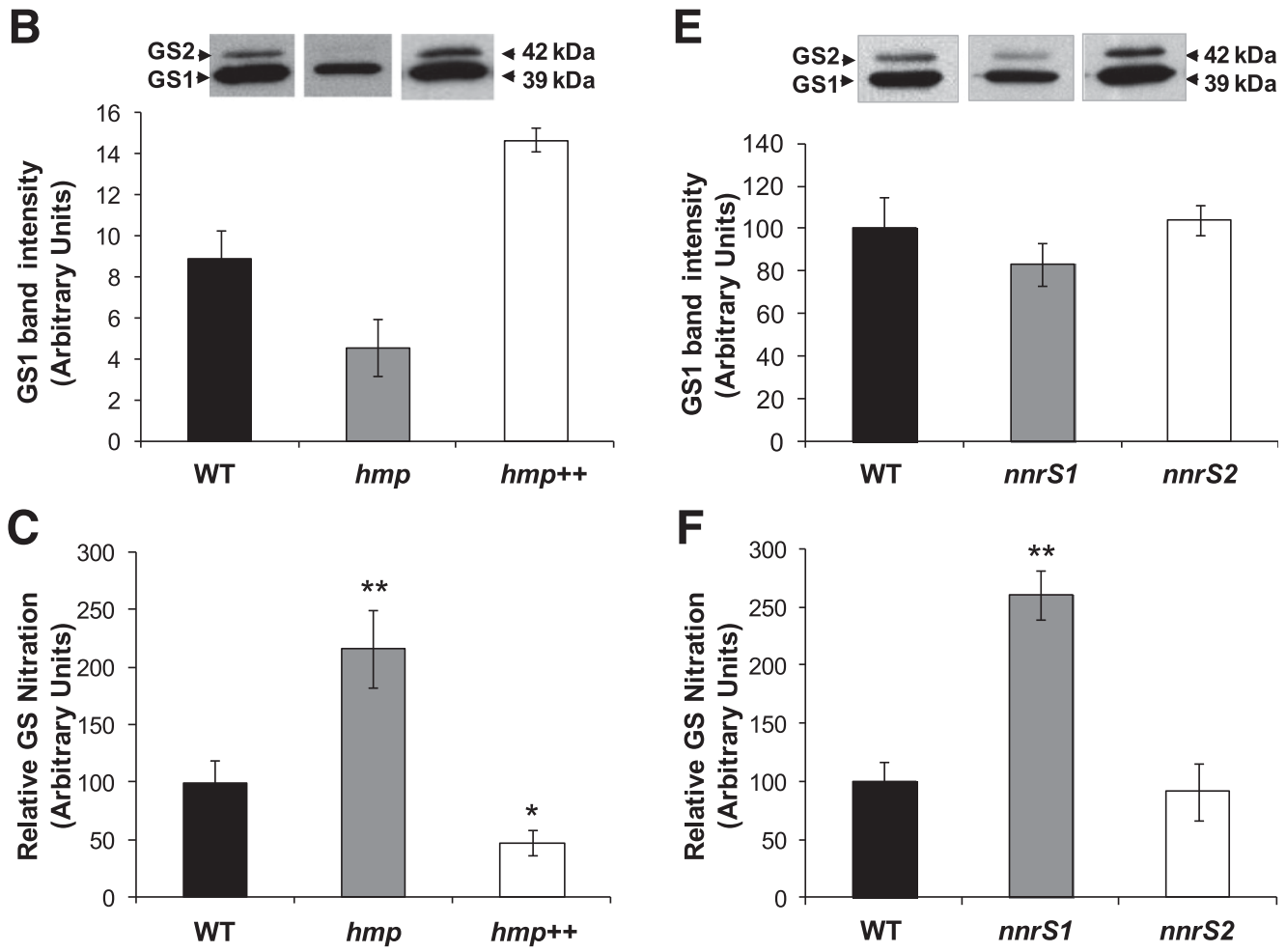

Fig. 6. Evaluation of glutamine synthetase (GS) nitration in nodules formed by Sinorhizobium meliloti hmp, hmp ${ }^{++}$, or $n n r S$ strains. Medicago truncatula seedlings were inoculated with S. meliloti strains GMI11495 (wild type [WT]), CBT613 (hmp), CBT602 (hmp ${ }^{++}$), CBT619 (nnrS1), or CBT1418 (nnrS2). Total soluble proteins were extracted from nodules collected at 3 weeks postinoculation. A and $\mathbf{D}$, GS activity was measured by the transferase reaction. B and $\mathbf{E}$, The cytosolic GS (GS1) immunoreactive bands were quantified by densitometry and the values were plotted. A representative GS Western blot of total soluble proteins ( $10 \mu \mathrm{g}$ per lane) is shown. $\mathbf{C}$ and $\mathbf{F}$, GS nitration was quantified by sandwich enzyme-linked immunosorbent assay relative to GS1 polypeptide content. GS nitration in the mutant nodules was normalized to that found in WT nodules. Mean values were obtained from three biological replicates \pm standard deviation, assayed in duplicate. Asterisks (* and **) indicate significant difference $(P<0.05$ and $P<0.01$, respectively) when compared with the control (WT strain), according to student's $t$ test. 
fluorescent dyes (DAF-2DA on nodule sections or DAF-2 for quantitative assays on entire nodules), and the second was based on the use of a $S$. meliloti NO biosensor strain (del Giudice et al. 2011). The amount of NO measured in the nnrS1elicited nodules was greater than that measured in the $h m p$ or nor $B$ nodules at $14 \mathrm{dpi}$ and was comparable after $18 \mathrm{dpi}$. In addition, both $n n r S$ mutant strains have been found to be more sensitive to NO when grown as free-living cells, as compared with a WT strain (P. Blanquet, unpublished data).

Altogether, these results suggest that $S$. meliloti $n n r S 1$ and $n n r S 2$ mutants are affected in their capacity to degrade NO. However, we cannot rule out the possibility that either NnrS1, $\mathrm{NnrS} 2$, or both could be involved in functions other than $\mathrm{NO}$ degradation. Indeed, it was recently suggested in $V$. cholerae that NnrS does not remove NO but might, instead, protect the cellular iron pool from NO damage (Stern et al. 2013). NnrS1 and NnrS2 from $S$. meliloti display a similar identity with the protein from V. cholerae (29.7 and $28.1 \%$, respectively) and one or both proteins could share a similar role. $n n r S 2$ is the first gene of an operon whose second gene (SMa1195) encodes a protein presenting homologies with YtfE proteins involved in the repair of NO damages to iron sulfur clusters (Justino et al. 2007, 2009). This gene neighborhood further supports their functional association.

Hence, S. meliloti possesses at least three systems (Hmp, Nor, NnrS1) to combat NO that are not redundant. These proteins might not have the same role or might not function in the same conditions inside nodules. Indeed, they have different localizations in the bacterial cell ( $\mathrm{Hmp}$ is cytosolic while the others are membrane proteins) and, on the other hand, they display different expression patterns within the different zones of the nodules (Meilhoc et al. 2013; Roux et al. 2014).

A rise in NO content inside nodules, caused by inoculation of plants with bacterial mutants deficient in NO degradation, triggers early nodule senescence. Our results show that, in these conditions, only bacteroid viability but not their release nor their differentiation in plant cells were affected. An intriguing question is whether bacteroid death is due to direct NO toxicity or is an indirect consequence of nodule-senescence induction. The second hypothesis might be favored, since bacteroids are in a nongrowing state close to that of stationary-phase bacteria (Capela et al. 2006), which could be more resistant to NO than cells in exponential growth phase, as resistance to NO increases with cell density (Supplementary Fig. S7). In addition, NO concentration inside the nodules was estimated to be in the micromole range (Meilhoc et al. 2010), which is lower than the NO concentration assayed in culture. However, we cannot completely exclude the possibility that the nodule microenvironment contains local elevated levels of $\mathrm{NO}$ or that the symbiosome membrane is very sensitive to $\mathrm{NO}$, as previously suggested (Puppo et al. 2005).

Hence, the interesting issue is why these bacterial proteins are so important for avoiding early nodule senescence and how they contribute to the maintenance of the symbiosis. The precise molecular mechanisms underlying the role of $\mathrm{NO}$ on nodule senescence are still poorly understood, but it is now recognized that NO can act by modifying target proteins via post-translational modifications (PTM). The major NOdependent PTM are i) the interaction of NO with metalloproteins (metal-nitrosylation), ii) the modification of tyrosine residues resulting in the formation of 3-nitrotyrosine, and iii) the formation of nitrosothiol groups on cysteine residues (Astier and Lindermayr 2012). These modifications occur in bacteria and in plant cells and, interestingly, these different types of NO-mediated PTM have been identified during symbiotic interactions. Indeed, leghemoglobin is metal-nitrosylated in nodules of soybean and this property was used to indirectly monitor NO levels (Sánchez et al. 2010). On the other hand, recent studies revealed that leghemoglobin is also tyrosine nitrated (Sainz et al. 2015). In addition, about 80 proteins have been shown recently to be $S$-nitrosylated in nodules of M. truncatula (Puppo et al. 2013). Finally one M. truncatula protein, GS, has been well characterized as a target of tyrosine nitration in root nodules (Melo et al. 2011). MtGS1a encodes the isoenzyme responsible for assimilation of the ammonia released by nitrogen fixation (Carvalho et al. 2000a and b). Interestingly, MtGS1a is subjected to tyrosine nitration, and this modification inhibits enzyme activity. This nitration appears to be somehow specific to the root nodules, as it was not observed in $M$. truncatula roots, and it has been suggested that it could be related to boosting the nodule antioxidant responses (Silva and Carvalho 2013).

Here, we show that, at 3 wpi, GS tyrosine nitration is about two- and 2.5-fold increased in nodules formed by hmp and nnrS1 mutants, respectively, as compared with WT nodules. This increase in GS nitration is associated with a decrease in GS activity in both cases. Conversely, hmp overexpression in bacteria leads to a decrease in GS nitration accompanied by an increase (about 50\%) in GS activity. Hence, the first major conclusion is that bacterial proteins involved in NO degradation are not only dedicated to protect bacterial proteins (for instance nitrogenase) from the effect of $\mathrm{NO}$ but to also protect plant proteins from being inactivated by $\mathrm{NO}$ via post-translational modifications. A similar observation was made in L. japonicus in which an increase in leghemoglobin metal-nitrosylation was observed in nodules occupied by a Bradyrhizobium japonicum nor mutant, especially under flooding stress conditions (Navascués et al. 2012; Sánchez et al. 2010).

Therefore, in nodules, the protection of plant proteins against NO is not an exclusive task of plant hemoglobins; bacterial and plant proteins could have an additive effect on the protection from the toxic effects of $\mathrm{NO}$ or, alternatively, bacterial proteins could be more efficient or more resistant to NO than plant hemoglobins. GS tyrosine nitration was reported to be increased in nodules elicited by a fixJ (nitrogen fixing-deficient) strain, indicating a link between nitrogen-fixation deficiency and the regulation of GS activity by tyrosine nitration (Melo et al. 2011). Since the expression of hmp is regulated by FixJ (Meilhoc et al. 2010), an alternative explanation could be that NO content is augmented in fixJ-elicited nodules, leading to an increase in GS nitration.

Altogether, our results show that the rate of GS tyrosine nitration is directly correlated with the NO levels inside the nodules and that the control of NO concentration by bacterial proteins limits nitration and subsequent inactivation of GS. Protein nitration is a chemical reaction generally thought to be due to the production of peroxynitrite $\left(\mathrm{ONOO}^{-}\right)$from $\mathrm{NO}$ and superoxide anions. We cannot exclude the possibility that reactive oxygen species (ROS) levels are also increasing in nodules occupied by the different bacterial mutants, hence, contributing to increase protein tyrosine nitration.

It is tempting to speculate that GS tyrosine nitration can be responsible for the initiation of nodule senescence. Indeed, an increased level of NO and ROS in aging nodules (Navascués et al. 2012; Puppo et al. 2005) could cause GS inhibition leading to a reduction in ammonia assimilation and induction of the senescence program as an end result. However, it seems unlikely that GS inhibition is the primary cause of nodule senescence, because transgenic plants specifically downregulated for MtGS1a in root nodules showed only about $60 \%$ of the WT nitrogen-fixation activity without presenting visible signs of nodule senescence $21 \mathrm{dpi}$ (H. Carvalho personal communication). Hence, we cannot exclude the possibility that other plant or bacterial proteins are also modified 
by an increase of NO and are responsible for induction of senescence. Finally, increased NO level in nodules might have pleiotropic effects that could also participate to the observed phenotypes.

In conclusion, this work identifies bacterial proteins important for maintaining an efficient symbiosis by contributing to the neutralization of the deleterious effects of NO, preventing the NO-mediated inactivation of GS and possibly other proteins important for root nodule functioning and, in this way, preventing early nodule senescence and maintaining nitrogenfixation activity. We demonstrate, for the first time, that bacteria can impact the course of nitrogen fixation by modulating the activity of a plant protein. Our future goal is to identify other proteins involved in this process, to help us better understand not only the natural process of nodule senescence but also the process of stress-induced senescence in which NO is also a key player. Nodule senescence is an overlooked step of nitrogenfixing symbiosis and needs to be better understood, as this knowledge can be used to extend the nitrogen-fixation period with obvious implications for forage legume yields.

\section{MATERIALS AND METHODS}

\section{Bacterial strains, plasmid constructions, and growth conditions.}

Bacterial strains and plasmids are listed in the Table 1.

$S$. meliloti strains were grown in Luria-Bertani medium supplemented with $2.5 \mathrm{mM} \mathrm{CaCl}_{2}$ and $2.5 \mathrm{mM} \mathrm{MgSO}_{4}$ (LBMC). NO resistance assays were performed in Vincent minimal medium as described by Meilhoc et al. 2010.

When necessary, antibiotics were added in the medium at the following concentrations $(\mu \mathrm{g} / \mathrm{ml})$ : streptomycin, 100 ; neomycin, 100; and gentamycin, 40.

The $S$. meliloti nnrS1 mutant strain was obtained from the mini-Tn5 transposon library described in Pobigaylo et al. 2006.

All plasmid constructions were performed in Escherichia coli $\mathrm{DH} 5 \alpha$. To construct the $n n r S 2$ mutant, the $5^{\prime}$ and $3^{\prime}$ flanking regions (326 and $317 \mathrm{bp}$, respectively) of $n n r S 2$ were amplified by polymerase chain reaction (PCR) by using genomic DNA of strain GMI11495 as template and the oligonucleotides
OCB1104(TGGATCCGAGCACCGAGGAT), OCB1105(TCG CGAGCTCGCGCGATAAA) and OCB1106(ACAGTCGACG AGCCACATGA), OCB1107 (AGGATCCCTGCTAAGTCGTG) as primers, respectively. The PCR fragments were then ligated with pGEM-T, yielding plasmids pGEM $5^{\prime}$ untranslated region (UTR) and pGEM 3' UTR, respectively (Table 1). The cloned $S$. meliloti regions were verified by DNA sequencing. The plasmids were digested with either enzymes SalI and BamHI or BamHI and SacI to collect the $3^{\prime}$ and 5' UTR DNA fragments, respectively. The UTRs were ligated with pJQ200mp19 (Table 1) digested by SalI and SacI, yielding pJQ200mp19 5'3'UTR nnrS2 (Table 1).

The plasmid was introduced into $S$. meliloti GMI11495 by triparental mating, using pRK2013 as helper, with subsequent selection for antibiotic resistance. Single-crossover genomic integration of the pJQ200mp19 5'3'UTR nnrS2 plasmid was generated by selecting for gentamycin resistance. The resulting strains were then grown in the absence of antibiotic, and cells having lost the plasmid by a second recombination event were selected by plating on LBMC medium supplemented with $5 \%$ sucrose, as the plasmid carries the $s a c B$ gene, which is lethal for $S$. meliloti in the presence of sucrose. A gentamycin-sensitive clone that grew on sucrose-containing medium was selected, and the deletion of $n n r S 2$ was verified by PCR using OCB905 (GATTTCGAACCCGGACAA) and OCB1467(CAACACCG TCGCAGC) primers.

To construct the pBBR-nnrS1 plasmid, the nnrS1 coding sequence with 100 nucleotides upstream of the start codon was amplified by PCR, by using genomic DNA of strain GMI11495 as template and oligonucleotides OCB1144(TCTAGACGGT GTCTTTGCCA) and OCB1145(GAGCTCCTATTGCACCGCC) as primers. The PCR fragment was then ligated with pGEM-T, yielding plasmid pGEM-nnrS1. The cloned region was verified by DNA sequencing. $n n r S 1$ was extracted from this plasmid by digestion with $X b a \mathrm{I}$ and $S a c I$ restriction enzymes and was then ligated in pBBRMCS5 cut by the same enzymes to give the plasmid pBBR-nnrS1 (Table 1). The plasmid was introduced into S. meliloti GMI11495 (WT) and CBT619 (nnrS1) strains by triparental mating, using pRK2013 as helper, with subsequent selection for antibiotic resistance.

Table 1. Strains and plasmids

\begin{tabular}{|c|c|c|}
\hline Strain or plasmid & Description $^{\text {a }}$ & Reference or source \\
\hline \multicolumn{3}{|l|}{ Sinorhizobium meliloti } \\
\hline GMI11495 & $\mathrm{Sm}^{\mathrm{r}}$ derivative of $\mathrm{Rm} 2011$ & Pobigaylo et al. 2006 \\
\hline Rm1021 & WT strain, SU-47 derived, $\mathrm{Sm}^{\mathrm{r}}$ & Meade et al. 1982 \\
\hline CBT619 & GMI11495 nnrS1::Tn5, $\mathrm{Sm}^{\mathrm{r}}, \mathrm{Nm}^{\mathrm{r}}$ & Pobigaylo et al. 2006 \\
\hline CBT1418 & GMI1 $1495 \Delta n n r S 2, \mathrm{Sm}^{\mathrm{r}}$ & This work \\
\hline CBT613 & GMI1 1495 hmp::Tn5, $\mathrm{Sm}^{\mathrm{r}}, \mathrm{Nm}^{\mathrm{r}}$ & Pobigaylo et al. 2006 \\
\hline CBT618 & GMI11495 norB $:: \mathrm{Tn} 5, \mathrm{Sm}^{\mathrm{r}}, \mathrm{Nm}^{\mathrm{r}}$ & Pobigaylo et al. 2006 \\
\hline CBT602 & GMI1 1495 containing pBBR- $h m p, \mathrm{Sm}^{\mathrm{r}}, \mathrm{Gm}^{\mathrm{r}}$ & Meilhoc et al. 2010 \\
\hline CBT778 & GMI1 1495 containing $\mathrm{pBBR}, \mathrm{Sm}^{\mathrm{r}}, \mathrm{Gm}^{\mathrm{r}}$ & del Giudice et al. 2011 \\
\hline CBT1564 & CBT619 containing pBBR, $\mathrm{Sm}^{\mathrm{r}}, \mathrm{Nm}^{\mathrm{r}}, \mathrm{Gm}^{\mathrm{r}}$ & This work \\
\hline CBT1516 & CBT619 containing pBBR- $n n r S 1, \mathrm{Sm}^{\mathrm{r}}, \mathrm{Nm}^{\mathrm{r}}, \mathrm{Gm}^{\mathrm{r}}$ & This work \\
\hline \multicolumn{3}{|l|}{ Escherichia coli } \\
\hline DH5 $\alpha$ & supE44 lacU169 hsdR17 recAl endA gyrA96 thi-1 relA1 & Invitrogen \\
\hline \multicolumn{3}{|c|}{ ple } \\
\hline pGEM-T & Cloning vector, $\mathrm{Ap}^{\mathrm{r}}$ & Promega \\
\hline pGEM 3' UTR & $3^{\prime}$ UTR $n n r S 2$ ligated with pGEM-T, Ap ${ }^{r}$ & This work \\
\hline pGEM 5' UTR & $5^{\prime}$ UTR $n n r S 2$ ligated with pGEM-T, Ap ${ }^{r}$ & This work \\
\hline pBBRMCS-5 & Cloning vector, $\mathrm{Gm}^{\mathrm{r}}$ & Kovach et al. 1995 \\
\hline pBBR-hmp & pBBRMCS-5 + hmp, $\mathrm{Gm}^{\mathrm{r}}$ & Meilhoc et al. 2010 \\
\hline pBBR-nnrS1 & pBBRMCS-5+nnrS1, Gm ${ }^{\mathrm{r}}$ & This work \\
\hline pJQ200mp19 & Gene replacement vector, $\mathrm{Gm}^{\mathrm{r}}$ & Sauviac et al. 2007 \\
\hline pJQ200 3'5'UTR nnrS2 & $3^{\prime} 5^{\prime} \mathrm{UTR} n n r S 2$ ligated with pJQ200, $\mathrm{Gm}^{\mathrm{r}}$ & This work \\
\hline psma1289-lacZ & Plasmid expressing a sma1289-lacZ reporter fusion, $\mathrm{Tc}^{\mathrm{r}}$ & del Giudice et al. 2011 \\
\hline pRK2013 & Helper plasmid for triparental matings, $\mathrm{Km}^{\mathrm{r}}$ & Figurski and Helinski 1979 \\
\hline
\end{tabular}




\section{Plant growth conditions.}

Medicago truncatula Jemalong A17 seedlings were usually grown in test tubes containing solid Farhaeus medium without a nitrogen source, as described by Lullien et al. (1987) and del Giudice et al. (2011). S. meliloti strains grown on LBMC plates were resuspended in sterile water to a final absorbance optical density at $600 \mathrm{~nm}\left(\mathrm{OD}_{600}\right)=0.001$, and plant roots were inoculated with $200 \mu \mathrm{l}$ of the bacterial suspension. For GS tyrosine nitration assays, plants of $M$. truncatula Jemalong J5 were grown in aeroponic conditions under 16 -h light $\left(22^{\circ} \mathrm{C}\right)$ and 8 -h dark $\left(19^{\circ} \mathrm{C}\right)$ cycles and under a light intensity of 150 to $200 \mu \mathrm{mol}$ $\mathrm{m}^{-2} \mathrm{~s}^{-1}$, in a growth medium supplemented with ammonium nitrate as described by Lullien et al. (1987). For nodule induction, the growth medium was replaced with fresh medium lacking a nitrogen source 3 days before inoculation with either $S$. meliloti GMI11495 (WT) or the mutant strains hmp (CBT613), nnrS1 (CBT619), nnrS2 (CBT1418), and $h m p^{++}$(CBT602). Nodules were harvested at $21 \mathrm{dpi}$. All plant material was immediately frozen in liquid nitrogen and was stored at $-80^{\circ} \mathrm{C}$.

\section{Assessment of nodule senescence.}

Nodule color shift observation. A series of 10 plants were inoculated with each bacterial genotype (WT or mutant). Every 2 days, nodules were observed under a binocular microscope. A nodule was considered to be senescent when a green area appeared at the nodule base (Supplementary Fig. S1). In each series, the numbers of senescent and total nodules were counted, and the percentage of senescent nodules was calculated. The experiment was repeated three times, and the mean of the percentage of senescent nodules was calculated from these three series.

Nodule electron microscopy and toluidine blue staining. Three-week-old nodules were fixed in $2.5 \%$ formaldehyde and $1.5 \%$ glutaraldehyde in $0.1 \mathrm{M}$ potassium phosphate buffer (KPi), $\mathrm{pH} 7.5$, with triton X-100 (0.01\%) for 45 min under vacuum, and then, left overnight at room temperature. Nodules were washed five times for $20 \mathrm{~min}$ in KPi buffer, five times in ultrapure water. The last wash was performed overnight. Nodules were then postfixed in $1 \% \mathrm{OsO}_{4}$ solution in water $(2 \mathrm{~h})$. After postfixation, nodules were carefully washed in ultrapure water for several days, and then, dehydrated in successive ethanol baths $(30,50,70,95,100 \%)$ and acetone $(100 \%)$, before impregnation and embedding in Spurr's resin (Electron Microscopy Science). After $8 \mathrm{~h}$ of polymerization, $2-\mu$ m-thick sections were cut (Ultracut, Reichert-Jung) and were stained with $0.1 \%$ toluidine blue- $0.2 \%$ methylene blue and $1 \%$ borax solution in water.

Ultrathin sections (70 to $80 \mathrm{~nm}$ ) were cut, were plated on 200-mesh copper grids, and were stained with $0.5 \%$ uranyl acetate in $50 \%$ ethanol. Observations were made with an Hitachi HT7700 transmission electron microscope.

Live and dead staining of bacteroids. Three-week-old nodules were harvested, were embedded in 5\% (wt/vol) agarose, and were cut with a Leica VT1200S vibratome. Nodule sections $(60 \mu \mathrm{m})$ were incubated for $20 \mathrm{~min}$ in live and dead staining solution (5.01 $\mu \mathrm{M}$ SYTO 9, $29.9 \mu \mathrm{M}$ PI) in Tris/HCl buffer $(50 \mathrm{mM})$, pH 7.0 (Live/Dead BacLight, Invitrogen). After three washes in deionized water, nodule sections were mounted in water and were observed with a Zeiss confocal microscope.

\section{Shoot dry weight.}

Plant shoots were carefully cut and were inserted in glass tubes. The dry weight of the shoots of about 30 plants was determined after incubation at $65^{\circ} \mathrm{C}$ for $72 \mathrm{~h}$.

\section{NO detection in root nodules.}

Quantification of NO by using the fluorescent DAF-2 probe. NO released from nodules was quantified by using the fluorescent nonpermeable DAF-2 probe (Sigma-Aldrich) as described by Horchani et al. (2011). Ten plants were inoculated with each bacterial genotype and their nodules were collected and pooled in a multiwell plate containing $1 \mathrm{ml}$ of Tris $\mathrm{HCl}(10 \mathrm{mM})$ and $\mathrm{KCl}(10 \mathrm{mM}), \mathrm{pH} 7.5$, with DAF-2 $(10 \mu \mathrm{M})$. Fluorescence was measured every $5 \mathrm{~min}$ for $3 \mathrm{~h}$, using a microplate reader spectrofluorimeter (Fluostar Omega, BMG Labtech) at $28^{\circ} \mathrm{C}$ (excitation wavelength, $495 \mathrm{~nm}$ and emission wavelength, $515 \mathrm{~nm}$ ). The slope of the curve was calculated and was expressed as fluorescence units per minute per milligram of wet nodules. In control experiments, a NO scavenger, cPTIO [2-(4-carboxylphenyl)4,4,5,5-tetramethyl imidazoline-1-oxyl-3-oxide] (1 $\mathrm{mM})$ (Sigma Aldrich) was added on WT-elicited nodules, $20 \mathrm{~min}$ before the addition of the DAF-2 probe, and the fluorescence measured in this condition was considered as NOnonspecific. cPTIO enhanced DAF-2 fluorescence, even in the absence of $\mathrm{NO}$; hence, the fluorescence measured when only cPTIO and DAF-2 were present in the reaction was deduced from the nonspecific fluorescence (in the presence of WT nodules) (Cam et al. 2012).

Detection of NO by confocal microscopy. Confocal microscopy experiments were performed on 19-dpi nodule sections $(60 \mu \mathrm{m})$ obtained with a vibratome (Leica VT1200S). Nodule sections were treated with DAF-2DA (Calbiochem), as described by Cam et al. 2012. As a control (nonspecific DAF2DA staining), nodule slices were pretreated with $1 \mathrm{mM}$ of the NO scavenger cPTIO for 15 min before treatment with the DAF-2DA probe. Observations were made with a confocal microscope (Leica SP2 AOBS), with excitation at $488 \mathrm{~nm}$ with an argon laser. Fluorescence emission was detected at $530 \mathrm{~nm}$. Images were processed and were analyzed using Leica software $3 \mathrm{~d}$.

Detection of NO by using NO biosensor strains. The NO biosensor consists in a reporter plasmid (psma1289-lacZ) (Table 1) carrying a transcriptional lacZ fusion to the S. meliloti SMa1289 gene promoter (del Giudice et al. 2011). Seedlings were inoculated with the different strains containing the NO biosensor. Three weeks postinoculation, nodule sections $(60 \mu \mathrm{m})$ obtained by using a Leica VT1200S vibratome were fixed in $\mathrm{Z}^{\prime}$ buffer $(0.1 \mathrm{M}$ phosphate buffer, $\mathrm{pH} 7.4$, $10 \mathrm{mM} \mathrm{KCl}, 1 \mathrm{mM} \mathrm{MgSO}_{4}$ ) with glutaraldehyde $(1.25 \%)$ under vacuum for $1.5 \mathrm{~h}$. The sections were then washed three times for $10 \mathrm{~min}$ with $\mathrm{Z}^{\prime}$ buffer and were incubated in the same buffer containing $5 \mathrm{mM}$ potassium ferricyanide, $5 \mathrm{mM}$ potassium ferrocyanide, and $0.8 \% \mathrm{X}$-gal. Nodule sections were incubated for $1 \mathrm{~h}$ under vacuum at room temperature and a further hour at $37^{\circ} \mathrm{C}$. Sections were observed in bright light optical microscopy (Axioplan imagin2; Zeiss). Pictures were taken with an AxioCam (Zeiss) and were processed with the corresponding software.

\section{Protein extraction from plant tissues.}

Root nodules of $M$. truncatula were homogenized at $4{ }^{\circ} \mathrm{C}$ with a mortar and pestle in two volumes of extraction buffer (phosphate-buffered saline [PBS], $\mathrm{pH} 7.4$, containing $0.05 \%$ Triton X-100 and $1 \mathrm{mM}$ phenylmethylsulfonyl fluoride), and the homogenates were centrifuged at $13,000 \times g$ for $20 \mathrm{~min}$ at $4^{\circ} \mathrm{C}$.

\section{Determination of GS activity.}

GS activity was determined using the transferase assay (Cullimore and Sims 1980). One unit of transferase activity is equivalent to $1 \mu \mathrm{mol} \mathrm{min}^{-1} \gamma$-glutamyl hydroxamate produced at $30^{\circ} \mathrm{C}$. Activity data were expressed as the mean \pm standard deviation of at least three independent experiments, with triplicate technical assays for each experiment. 
Protein determination, sodium dodecyl sulfate-polyacryamide gel electrophoresis (SDS-PAGE) and Western blot analysis.

Soluble protein concentration was measured by the Coomassie dye-binding assay (BioRad) using bovine serum albumin (BSA) as a standard. Soluble protein extracts were separated by $12.5 \%$ (wt/vol) SDS-PAGE and were electroblotted onto nitrocellulose membranes (Schleicher and Schuell) using a Criterion Blotter from BioRad.

GS immunodetection was carried out using rabbit serum antibody raised against a GS isoform from Phaseolus vulgaris (provided by J. Cullimore from INRA Toulouse (Cullimore et al. 1984) and a secondary goat antirabbit peroxidase conjugated antibody (Vector Laboratories). The immunocomplexes were detected by chemiluminescence, using the ECL (GE Healthcare, Lifesciences) detection system with a photographic film. Representative blots of at least three independent experiments are shown in Figure 6. GS protein quantification was performed using the Molecular imager GS800 calibrated densitometer (Bio-Rad) and Quantity 1-D Analysis software (Bio-Rad).

\section{Quantification of nitrated GS by ELISA.}

A microtiter plate (F8 Maxisorp Nunc-Immuno module; Nunc) was coated with the antiglnA-antibody (Cullimore et al. 1984) diluted in PBS $(50 \mu \mathrm{l}$ per well) and were incubated overnight at $4^{\circ} \mathrm{C}$. After two washings (PBS, pH 7.4, 0.5\% Tween 20), the plate was blocked (PBS, pH 7.4, 3\% BSA, $100 \mu \mathrm{l}$ per well) for $2 \mathrm{~h}$ at room temperature. The blocking buffer was removed, and the plant extracts were diluted in extraction buffer to $10 \mu \mathrm{g}$ in $50 \mu \mathrm{l}$ and the calibration standard solution was added to the plate $(50 \mu \mathrm{l}$ per well) and was incubated for $4 \mathrm{~h}$ at room temperature. All experiments were performed in duplicate. After five washings, a diluted biotinlabeled monoclonal antibody against 3-nitrotyrosine (100 $\mu \mathrm{l}$ per well; Cayman Chemicals) was added to the plate and was incubated for $2 \mathrm{~h}$ at room temperature. After washing, a NeutrAvidin-HRP-conjugate (Invitrogen) was added to the plate and was incubated for $1 \mathrm{~h}$ at room temperature.

The plates were washed four times with wash buffer, before adding $100 \mu \mathrm{l}$ per well of $p$-nitrophenyl phosphate substrate (Sigma Fast; Sigma-Aldrich Inc.). The plates were incubated in the dark for $30 \mathrm{~min}$ at room temperature before stopping the reaction by the addition of $100 \mu \mathrm{l}$ per well of $0.25 \mathrm{M} \mathrm{HCl}$. The absorbance was measured at $490 \mathrm{~nm}$, using a microplate reader ( $\mu$ Quant Microplat Spec; Biotek). Standard curves were established by serial dilutions ( 1 to $5 \mathrm{ng}$ ) of in vitro nitrated GS per well. For this purpose, E. coli-produced MtGS1a was purified and preincubated with $100 \mu \mathrm{M}$ peroxynitrite for $15 \mathrm{~min}$ at room temperature. Since it is not possible to ensure that GS is nitrated to completion in the in vitro nitration assays of the standards used for the quantification, GS nitration values are presented as arbitrary units in relation to the relative amount of cytosolic GS polypeptides quantified by densitometry. The GS nitration values for the mutant nodules were normalized to the WT and are presented as percentage of WT.

\section{ACKNOWLEDGMENTS}

We thank A. Becker (University of Bielefeld, Germany) for giving us some S. meliloti mutants. We are grateful to L. Sauviac and P. Dupuy for many helpful discussions and technical support. We gratefully acknowledge J. Cullimore for providing GS antibody. P. Blanquet is the recipient of a Contrat Jeune Scientifique INRA. E. Meilhoc was supported by the National Institute for Applied Sciences (INSA-Toulouse). This work was supported by the French Laboratory of Excellence project "TULIP" (ANR-10-LABX-41 and ANR-11-IDEX-0002-02), by community funds (FEDER) through the Operational Competitiveness Program COMPETE, and by Fundação para a Ciência e a Tecnologia (FCT) under the project FCOMP-01-0124-FEDER-028335 (PTDC/BIA-PLA/2291/2012).

\section{LITERATURE CITED}

Abello, N., Kerstjens, H. A., Postma, D. S., and Bischoff, R. 2009. Protein tyrosine nitration: Selectivity, physicochemical and biological consequences, denitration, and proteomics methods for the identification of tyrosine-nitrated proteins. J. Proteome Res. 8:3222-3238.

Arai, H., Roh, J. H., Eraso, J. M., and Kaplan, S. 2013. Transcriptome response to nitrosative stress in Rhodobacter sphaeroides 2.4.1. Biosci. Biotechnol. Biochem. 77:111-118.

Astier, J., and Lindermayr, C. 2012. Nitric oxide-dependent posttranslational modification in plants: An update. Int. J. Mol. Sci. 13:1519315208.

Bartnikas, T. B., Wang, Y., Bobo, T., Veselov, A., Scholes, C. P., and Shapleigh, J. P. 2002. Characterization of a member of the NnrR regulon in Rhodobacter sphaeroides 2.4 .3 encoding a haem-copper protein. Microbiology 148:825-833.

Baudouin, E., Pieuchot, L., Engler, G., Pauly, N., and Puppo, A. 2006 Nitric oxide is formed in Medicago truncatula-Sinorhizobium meliloti functional nodules. Mol. Plant-Microbe Interact. 19:970-975.

Begara-Morales, J. C., Chaki, M., Sánchez-Calvo, B., Mata-Pérez, C., Leterrier, M., Palma, J. M., Barroso, J. B., and Corpas, F. J. 2013. Protein tyrosine nitration in pea roots during development and senescence. J. Exp. Bot. 64:1121-1134.

Besson-Bard, A., Pugin, A., and Wendehenne, D. 2008. New insights into nitric oxide signaling in plants. Annu. Rev. Plant Biol. 59:21-39.

Bowman, L. A., McLean, S., Poole, R. K., and Fukuto, J. M. 2011. The diversity of microbial responses to nitric oxide and agents of nitrosative stress close cousins but not identical twins. Adv. Microb. Physiol. 59: 135-219.

Cam, Y., Pierre, O., Boncompagni, E., Hérouart, D., Meilhoc, E., and Bruand, C. 2012. Nitric oxide (NO): A key player in the senescence of Medicago truncatula root nodules. New Phytol. 196:548-560.

Capela, D., Filipe, C., Bobik, C., Batut, J., and Bruand, C. 2006. Sinorhizobium meliloti differentiation during symbiosis with alfalfa: A transcriptomic dissection. Mol. Plant-Microbe Interact. 19:363-372.

Carvalho, H., Lescure, N., de Billy, F., Chabaud, M., Lima, L., Salema, R., and Cullimore, J. 2000a. Cellular expression and regulation of the Medicago truncatula cytosolic glutamine synthetase genes in root nodules. Plant Mol. Biol. 42:741-756.

Carvalho, H., Lima, L., Lescure, N., Camut, S., Salema, R., and Cullimore, J. 2000b. Differential expression of the two cytosolic glutamine synthetase genes in various organs of Medicago truncatula. Plant Sci. 159:301-312.

Cullimore, J. V., Gebhardt, C., Saarelainen, R., Miflin, B. J., Idler, K. B., and Barker, R. F. 1984. Glutamine synthetase of Phaseolus vulgaris L.: Organ-specific expression of a multigene family. J. Mol. Appl. Genet. 2: 589-599.

Cullimore, J. V., and Sims, A. P. 1980. An association between photorespiration and protein catabolism: Studies with Chlamydomonas. Planta 150:392-396.

de Bruijn, F. J., Rossbach, S., Bruand, C., and Parrish, J. R. 2006. A highly conserved Sinorhizobium meliloti operon is induced microaerobically via the FixLJ system and by nitric oxide (NO) via NnrR. Environ. Microbiol. 8:1371-1381.

del Giudice, J., Cam, Y., Damiani, I., Fung-Chat, F., Meilhoc, E., Bruand, C., Brouquisse, R., Puppo, A., and Boscari, A. 2011. Nitric oxide is required for an optimal establishment of the Medicago truncatulaSinorhizobium meliloti symbiosis. New Phytol. 191:405-417.

Figurski, D. H., and Helinski, D. R. 1979. Replication of an origincontaining derivative of plasmid RK2 dependent on a plasmid function provided in trans. Proc. Natl. Acad. Sci. U.S.A. 76:1648-1652.

Filippou, P., Antoniou, C., Yelamanchili, S., and Fotopoulos, V. 2012. NO loading: Efficiency assessment of five commonly used application methods of sodium nitroprusside in Medicago truncatula plants. Plant Physiol. Biochem. 60:115-118

Gupta, K. J., Hebelstrup, K. H., Mur, L. A., and Igamberdiev, A. U. 2011 Plant hemoglobins: Important players at the crossroads between oxygen and nitric oxide. FEBS (Fed. Eur. Biochem. Soc.) Lett. 585:3843-3849.

Horchani, F., Prévot, M., Boscari, A., Evangelisti, E., Meilhoc, E., Bruand, C., Raymond, P., Boncompagni, E., Aschi-Smiti, S., Puppo, A., and Brouquisse, R. 2011. Both plant and bacterial nitrate reductases contribute to nitric oxide production in Medicago truncatula nitrogenfixing nodules. Plant Physiol. 155:1023-1036.

Jamet, A., Euphrasie, D., Martin, P., and Nassif, X. 2013. Identification of genes involved in Neisseria meningitidis colonization. Infect. Immun. 81:3375-3381. 
Jones, K. M., Kobayashi, H., Davies, B. W., Taga, M. E., and Walker, G. C. 2007. How rhizobial symbionts invade plants: The SinorhizobiumMedicago model. Nat. Rev. Microbiol. 5:619-633.

Justino, M. C., Almeida, C. C., Teixeira, M., and Saraiva, L. M. 2007. Escherichia coli di-iron YtfE protein is necessary for the repair of stressdamaged iron-sulfur clusters. J. Biol. Chem. 282:10352-10359.

Justino, M. C., Baptista, J. M., and Saraiva, L. M. 2009. Di-iron proteins of the Ric family are involved in iron-sulfur cluster repair. Biometals 22: 99-108.

Kato, K., Kanahama, K., and Kanayama, Y. 2010. Involvement of nitric oxide in the inhibition of nitrogenase activity by nitrate in Lotus root nodules. J. Plant Physiol. 167:238-241.

Kovach, M. E., Elzer, P. H., Hill, D. S., Robertson, G. T., Farris, M. A., Roop, R. M., 2nd, and Peterson, K. M. 1995. Four new derivatives of the broad-host-range cloning vector pBBR1MCS, carrying different antibiotic-resistance cassettes. Gene 166:175-176.

Lullien, V., Barker, D. G., de Lajudie, P., and Huguet, T. 1987. Plant gene expression in effective and ineffective root nodules of alfalfa (Medicago sativa). Plant Mol. Biol. 9:469-478.

Mathieu, C., Moreau, S., Frendo, P., Puppo, A., and Davies, M. J. 1998. Direct detection of radicals in intact soybean nodules: Presence of nitric oxide-leghemoglobin complexes. Free Radic. Biol. Med. 24:1242-1249.

Meade, H. M., Long, S. R., Ruvkun, G. B., Brown, S. E., and Ausubel, F. M. 1982. Physical and genetic characterization of symbiotic and auxotrophic mutants of Rhizobium meliloti induced by transposon Tn5 mutagenesis. J. Bacteriol. 149:114-122.

Meilhoc E., Blanquet P., Cam Y. and Bruand C. 2013. Control of NO level in rhizobium-legume root nodules: Not only a plant globin story. Plant Signal. Behav. 8:10.

Meilhoc, E., Boscari, A., Bruand, C., Puppo, A., and Brouquisse, R. 2011. Nitric oxide in legume-rhizobium symbiosis. Plant Sci. 181:573-581.

Meilhoc, E., Cam, Y., Skapski, A., and Bruand, C. 2010. The response to nitric oxide of the nitrogen-fixing symbiont Sinorhizobium meliloti. Mol. Plant-Microbe Interact. 23:748-759.

Melo, P. M., Silva, L. S., Ribeiro, I., Seabra, A. R., and Carvalho, H. G. 2011. Glutamine synthetase is a molecular target of nitric oxide in root nodules of Medicago truncatula and is regulated by tyrosine nitration. Plant Physiol. 157:1505-1517.

Mur, L. A., Carver, T. L., and Prats, E. 2006. NO way to live: the various roles of nitric oxide in plant-pathogen interactions. J. Exp. Bot. 57: 489-505.

Mur, L. A., Mandon, J., Persijn, S., Cristescu, S. M., Moshkov, I. E., Novikova, G. V., Hall, M. A., Harren, F. J. M., Hebelstrup, K. H., and Gupta, K. J. 2012. Nitric oxide in plants: An assessment of the current state of knowledge. AoB Plants 5:pls052.

Nagata, M., Murakami, E., Shimoda, Y., Shimoda-Sasakura, F., Kucho, K., Suzuki, A., Abe, M., Higashi, S., and Uchiumi, T. 2008. Expression of a class 1 hemoglobin gene and production of nitric oxide in response to symbiotic and pathogenic bacteria in Lotus japonicus. Mol. PlantMicrobe Interact. 21:1175-1183.

Navascués, J., Pérez-Rontomé, C., Gay, M., Marcos, M., Yang, F., Walker, F. A., Desbois, A., Abián, J., and Becana, M. 2012. Leghemoglobin green derivatives with nitrated hemes evidence production of highly reactive nitrogen species during aging of legume nodules. Proc. Natl. Acad. Sci. U.S.A. 109:2660-2665.

Oldroyd, G. E., Murray, J. D., Poole, P. S., and Downie, J. A. 2011. The rules of engagement in the legume-rhizobial symbiosis. Annu. Rev. Genet. 45:119-144.

Pei, J., Li, W., Kinch, L. N., and Grishin, N. V. 2014. Conserved evolutionary units in the heme-copper oxidase superfamily revealed by novel homologous protein families. Protein Sci. 23:1220-1234.

Pii, Y., Crimi, M., Cremonese, G., Spena, A., and Pandolfini, T. 2007. Auxin and nitric oxide control indeterminate nodule formation. BMC Plant Biol. 7: 21
Pobigaylo, N., Wetter, D., Szymczak, S., Schiller, U., Kurtz, S., Meyer, F., Nattkemper, T. W., and Becker, A. 2006. Construction of a large signature-tagged mini-Tn5 transposon library and its application to mutagenesis of Sinorhizobium meliloti. Appl. Environ. Microbiol. 72: 4329-37.

Procházková, D., and Wilhelmová, N. 2011. Nitric oxide, reactive nitrogen species and associated enzymes during plant senescence. Nitric Oxide 24:61-65.

Puppo, A., Groten, K., Bastian, F., Carzaniga, R., Soussi, M., Lucas, M. M., de Felipe, M. R., Harrison, J., Vanacker, H., and Foyer, C. H. 2005 Legume nodule senescence: Roles for redox and hormone signalling in the orchestration of the natural aging process. New Phytol. 165:683-701.

Puppo, A., Pauly, N., Boscari, A., Mandon, K., and Brouquisse, R. 2013. Hydrogen peroxide and nitric oxide: Key regulators of the LegumeRhizobium and mycorrhizal symbioses. Antioxid. Redox Signal. 18: 2202-2219.

Roux, B., Rodde, N., Jardinaud, M. F., Timmers, T., Sauviac, L., Cottret, L., Carrère, S., Sallet, E., Courcelle, E., Moreau, S., Debellé, F., Capela, D. de Carvalho-Niebel, F., Gouzy, J., Bruand, C., and Gamas, P. 2014. An integrated analysis of plant and bacterial gene expression in symbiotic root nodules using laser-capture microdissection coupled to RNA sequencing. Plant J. 77:817-837.

Sainz, M., Calvo-Begueria, L., Pérez-Rontomé, C., Wienkoop, S., Abián, J., Staudinger, C., Bartesaghi, S., Radi, R., and Becana, M. 2015. Leghemoglobin is nitrated in functional legume nodules in a tyrosine residue within the heme cavity by a nitrite/peroxide-dependent mechanism. Plant J. 81:723-735.

Sánchez, C., Gates, A. J., Meakin, G. E., Uchiumi, T., Girard, L., Richardson, D. J., Bedmar, E. J., and Delgado, M. J. 2010. Production of nitric oxide and nitrosylleghemoglobin complexes in soybean nodules in response to flooding. Mol. Plant-Microbe Interact. 23:702-711.

Sauviac, L., Philippe, H., Phok, K., and Bruand, C. 2007. An extracytoplasmic function sigma factor acts as a general stress response regulator in Sinorhizobium meliloti. J. Bacteriol. 189:4204-4216.

Silva, L., and Carvalho, H. 2013. Possible role of glutamine synthetase in the NO signaling response in root nodules by contributing to the antioxidant defenses. Front. Plant Sci. 4:372-380.

Sousa, F. L., Alves, R. J., Ribeiro, M. A., Pereira-Leal, J. B., Teixeira, M., and Pereira, M. M. 2012. The superfamily of heme-copper oxygen reductases: Types and evolutionary considerations. Biochim. Biophys. Acta 1817:629-637.

Stern, A. M., Hay, A. J., Liu, Z., Desland, F. A., Zhang, J., Zhong, Z., and Zhu, J. 2012. The NorR regulon is critical for Vibrio cholerae resistance to nitric oxide and sustained colonization of the intestines. MBio 3: e00013-12.

Stern, A. M., Liu, B., Bakken, L. R., Shapleigh, J. P., and Zhu, J. 2013. A novel protein protects bacterial iron-dependent metabolism from nitric oxide. J. Bacteriol. 195:4702-4708.

Stern, A. M., and Zhu, J. 2014. An introduction to nitric oxide sensing and response in bacteria. Adv. Appl. Microbiol. 87:187-220.

Terpolilli, J. J., Hood, G. A., and Poole, P. S. 2012. What determines the efficiency of $\mathrm{N}_{2}$-fixing Rhizobium-legume symbioses? Adv. Microb. Physiol. 60:325-389.

Timmers, A. C., Soupène, E., Auriac, M. C., de Billy, F., Vasse, J., Boistard, P., and Truchet, G. 2000. Saprophytic intracellular rhizobia in alfalfa nodules. Mol. Plant-Microbe Interact. 13:1204-1213.

Trinchant, J. C., and Rigaud, J. 1982. Nitrite and nitric oxide as inhibitors of nitrogenase from soybean bacteroids. Appl. Environ. Microbiol. 44: 1385-1388.

Wang, Y., and Ruby, E. G. 2011. The roles of NO in microbial symbioses. Cell. Microbiol. 13:518-526.

Yu, M., Lamattina, L., Spoel, S. H., and Loake, G. J. 2014. Nitric oxide function in plant biology: A redox cue in deconvolution. New Phytol. 202:1142-1156. 